\title{
A clínica da psicose: uma direção à possibilidade
}

\author{
The psychosis clinic: a direction to possibility
}

La clínica de psicosis: una dirección a la posibilidad

Fernanda Gonçalves de Abreu Rocha de Morais ${ }^{1}$, Rayssa Caroline de Oliveira1', Ricardo Otávio Maia Gusmão'.

\section{RESUMO}

Objetivo: Produzir considerações teóricas e críticas acerca das especificidades à clínica da psicose a partir das contribuições da psicanálise por meio de revisão narrativa. Revisão Bibliográfica: Em Freud, utilizouse: "Caso Schereber" (1911/1996), "Introdução ao narcisismo" (1914/1996), "A teoria da libido e o narcisismo" (1916-1917/1996), "Neurose e Psicose" e "A perda da realidade na Neurose e Psicose", ambos de (1924/1996). Em Lacan, usou-se: "Seminário - livro 3 "As Psicoses" (1955-6/1998) e "De uma questão preliminar a todo tratamento possível na psicose" (1958/1998). Além disso, artigos de estudiosos de Freud e de Lacan foram usados. A discussão foi apresentada através dos seguintes tópicos: Teoria do narcisismo na psicose; As manifestações de corpo na clínica da psicose; O desencadeamento psicótico e a estabilização; A questão da transferência na psicose; e Impasses institucionais na clínica da psicose. Considerações Finais: As alterações no processo da linguagem implicam nas manifestações bem características dessa clínica, como exemplo acontecimentos de corpo, alucinações e delírios. Apesar disso, Lacan em seu ensino propõe a possibilidade de pensar o manejo da transferência na clínica da psicose pela via do secretariado.

Palavras-Chave: Psicanálise, Psicose, Clínica.

\begin{abstract}
Objective: To produce theoretical and critical considerations about the specifics to the clinic of psychosis from the contributions of psychoanalysis through narrative review. Literature review: In Freud, we used: "Case Schereber" (1911/1996), "Introduction to narcissism" (1914/1996), "The libido theory and narcissism" (19161917 / 1996), "Neurosis and Psychosis "and" The Loss of Reality in Neurosis and Psychosis ", both from (1924/1996). In Lacan, we used: "Seminar - Book 3" The Psychoses "(1955-6 / 1998) and" From a preliminary question to every possible treatment in psychosis "(1958/1998). In addition, articles by scholars of Freud and Lacan were used. The discussion was presented through the following topics: Theory of narcissism in psychosis; Body manifestations in psychosis clinic; Psychotic triggering and stabilization; The issue of transference in psychosis; and Institutional impasses in the clinic of psychosis. Final Considerations: Changes in the language process imply the very characteristic manifestations of this clinic, such as body events, hallucinations and delusions. Nevertheless, Lacan in his teaching proposes the possibility of thinking about the transference management in the clinic of psychosis through the secretariat.
\end{abstract}

Keyword: Psychoanalysis, Psychosis, Clinic.

\section{RESUMEN}

Objetivo: Producir consideraciones teóricas y críticas sobre los aspectos específicos de la clínica de psicosis a partir de las contribuciones del psicoanálisis a través de la revisión narrativa. Revisión bibliográfica: En Freud, usamos: "Case Schereber" (1911/1996), "Introducción al narcisismo" (1914/1996), "La teoría de la libido y el narcisismo" (1916-1917 / 1996), "Neurosis y psicosis "y" La pérdida de la realidad en la neurosis y la psicosis ", de (1924/1996). En Lacan se utilizó: "Seminario - Libro 3" Las psicosis "(1955-6 / 1998) y" De una pregunta preliminar a cada posible tratamiento en la psicosis "(1958/1998) y artículos de eruditos de

\footnotetext{
${ }^{1}$ Universidade Estadual de Montes Claros-UNIMONTES, Montes Claros, MG.

*E-mail: ricardotavio25@gmail.com
} 
Freud y Lacan. La discusión se presentó con siguientes temas: teoría del narcisismo en la psicosis; Manifestaciones corporales en clínica de psicosis; Activación psicótica y estabilización; El tema de la transferencia en psicosis; e impases institucionales en la clínica de psicosis. Consideraciones finales: Alteraciones en el proceso del lenguaje implican manifestaciones muy características de esta clínica, como eventos corporales, alucinaciones y delirios. Sin embargo, Lacan en su enseñanza propone la posibilidad de pensar en el manejo de la transferencia a través de la secretaría.

Palabras clave: Psicoanálisis, Psicosis, Clínica.

\section{INTRODUÇÃO}

A prática clínica com a psicose produz enigmas que se apresentam no contexto da Atenção Psicossocial e instituições. Faz-se importante acentuar que, na clínica da psicose, nos deparamos com algumas problemáticas que geram impasses ao trabalho clínico dos profissionais no campo da saúde mental. Nesse sentido, os embaraços da clínica e as questões que são produzidas nesse contexto nos convocam a buscar contribuições às especificidades na clínica da psicose junto aos referenciais teóricos da psicanálise (GUSMÃO ROM, 2016).

Freud, no primeiro momento de sua obra, ao fazer o estudo psicopatológico dos quadros clínicos e experiências de sofrimento mental, pensou o sintoma na sua relação com o inconsciente, desejo e defesa, de maneira a proporcionar a ele a dimensão do sentido (GUERRA AMC, 2010).

Sobre as neuroses narcísicas, posteriormente denominadas de psicoses, Freud acreditava inicialmente haver a impossibilidade de tratamento. O psicótico, em seu funcionamento narcísico, não deslocaria a libido do seu próprio eu para a figura do profissional, impossibilitando a relação de amor transferencial dentro do processo analítico devido ao seu desinvestimento objetal (FREUD S, 1916/1996).

Nesse momento inicial da obra psicanalítica freudiana, o método utilizado como recurso analítico era a interpretação. Isso porque, tradicionalmente, Freud deu à sua obra certo privilégio no estudo das neuroses, contudo, à medida que a psicanálise avançava, outras possibilidades terapêuticas foram pensadas (FREUD S, 1924/1996).

É importante ressaltar que, no campo da psicose, não se trata de interpretar, já que temos uma clínica do real (não há o que se decifrar), os parâmetros terapêuticos são outros. Quem vai fazer essa leitura posteriormente com o retorno à obra freudiana, utilizando-se de outros recursos para a construção teórica desta clínica, é Lacan (GUERRA AMC, 2010).

Lacan lançou mão da obra freudiana para introduzir-se na psicanálise. Toda a sua trajetória inicialmente ocorreu no estudo da psicose, sendo o primeiro trabalho que o inaugura na psicanálise a sua tese de doutorado que produziu sobre a paranoia em 1932. O retorno à obra freudiana vai permitir a Lacan discutir e avançar sobre as especificidades da clínica da psicose, diferenciando-a inicialmente da clínica da neurose e apresentando considerações a respeito do tratamento psicanalítico possível nesse campo (LACAN J, 19556/ 1998).

O desejo de Lacan pela psicose o motivou a construir um percurso dando a ela um destaque. Isso porque, ao mesmo tempo em que Freud pouco avançou com essa clínica, produziu indicações preciosas que ainda precisavam ter prosseguimento (LACAN J, 1955/ 1998).

Lacan em seus ensinamentos nos convoca a não recuar frente à clínica da psicose. Tal leitura nos permite compreender que é preciso estabelecer uma "clínica do sujeito", também para esses casos (GUERRA AMC, 2010).

Explicitamos o interesse de esclarecimento das seguintes questões: o funcionamento narcísico na psicose cuja resultante é a dificuldade com o laço social; o corpo e seu protagonismo na psicose, os sintomas corporais e o que eles revelam das psicoses; o desencadeamento da psicose e o seu mecanismo constitutivo; as particularidades da transferência na psicose. 
Para tal propósito, fez-se um percurso em Freud e Lacan, objetivando resgatar contribuições à clínica da psicose. Em Freud, utilizou-se: "Caso Schereber" (1911/1996), "Introdução ao narcisismo" (1914/1996), "A teoria da libido e o narcisismo" (1916-1917/1996), "Neurose e Psicose" e "A perda da realidade na Neurose e Psicose", ambos de (1924/1996). Em Lacan, os textos que sustentaram a discussão foram: "Seminário - livro 3 "As Psicoses" (1955-6/1998) e "De uma questão preliminar a todo tratamento possível na psicose" (1958/ 1998). Além disso, artigos de autores estudiosos de Freud e de Lacan foram usados.

A discussão foi apresentada através dos seguintes tópicos: Teoria do narcisismo na psicose; As manifestações de corpo na clínica da psicose; O desencadeamento psicótico e a estabilização; A questão da transferência na psicose; e Impasses institucionais na clínica da psicose.

Assim, este estudo de revisão narrativa teve por objetivo produzir considerações teóricas e críticas acerca das especificidades à clínica da psicose a partir das contribuições da psicanálise. Busca-se, a partir de questões que emergem da clínica teoriza-las por meio da teoria psicanalítica.

\section{REVISÃO BIBLIOGRÁFICA}

\section{Teoria do narcisismo e psicose}

Na clínica da psicose, chama-se atenção o isolamento e a precariedade nos vínculos afetivos relatados pelos pacientes. A partir de certo momento da vida, é comum o desinvestimento pulsional em objetos externos e no laço social. Passa a concentrar sua libido sobre o seu "eu" mediante uma retração narcísica da libido. Posteriormente, tem-se o início de sintomas que persistem na sua vida cujo destaque reflete em sua expressão corporal (GUSMÃO ROM, 2016).

Freud, ao teorizar as suas ideias sobre os fenômenos clínicos das psicoses, utilizou como base conceitual suas formulações sobre o narcisismo. A partir desse conceito fundamental, é possível compreender as peculiaridades que se apresentam nessa clínica. Ressalta-se que o narcisismo é o elemento marcante na psicose e o ponto de partida para pensar nas especificidades dessa clínica. Freud constatou que 0 desligamento da libido objetal advinha de uma frustração nas relações do sujeito com a realidade externa (FREUD S, 1914/1996).

As elaborações teóricas sobre o narcisismo foram elucidadas no estudo do "Caso Schreber", 1911/1996, um caso clínico analisado por Freud, no qual observou que, ao retirar a libido do mundo externo e redirecionála para o "eu", Schreber revivencia o amor egoístico, o que o leva a um excesso de narcisismo. Essa formulação é retomada no texto "Introdução ao Narcisismo", 1914. Naquele momento, Freud relaciona, em seus estudos, a paranoia como um quadro clínico resultante de uma defesa contra o impulso da libido homossexual relacionada com o narcisismo. O que pode se extrair dessa formulação inicial é o destaque dado por Freud a uma relação entre psicose e funcionamento narcísico.

No fim do artigo de (1911/1996), Freud destaca as especificidades que envolvem os quadros clínicos paranoia e esquizofrenia. Para Freud, a paranoia deveria ser mantida como um tipo clínico diferente da esquizofrenia. Entretanto, sustenta a ideia de mecanismos similares. Seguindo as suas postulações sobre a teoria da libido, diante da repressão, nesses casos, o deslizamento da libido regrediria até o eu, uma regressão narcisista. A diferença decorreria do ponto de fixação dessa libido, o que justificaria sintomatologias distintas.

$\mathrm{Na}$ esquizofrenia, a regressão libidinal passa pelo narcisismo, mas se estenderia ainda mais, retornando ao autoerotismo infantil, no mais "completo abandono do amor objetal" (FREUD S, 19911/1996). Esse retorno ao autoerotismo justificaria a manifestação de fenômenos hipocondríacos ou corporais. Na paranoia, por sua vez, haveria uma fixação da pulsão na fase do narcisismo. No entanto, embora cada quadro clínico apresente um ponto de fixação libidinal definido, isso não impossibilitaria que a libido perpassasse outros pontos e que, com isso, novos fenômenos sobrevenham (FREUD S, 1911/1996).

No texto "Introdução ao narcisismo" (1914/1996), Freud retoma discussões teóricas cruciais sobre a tentativa de reestabelecimento da libido na paranoia e na esquizofrenia. Na paranoia, esse movimento se fará 
pela via do pensamento, constituindo, no final, a megalomania e se estabelecendo através do delírio de grandeza. Na esquizofrenia, por sua vez, o reestabelecimento acontecerá de forma prevalente, mediante a construção de vivências alucinatórias relacionadas a acontecimentos voltados para o corpo (GUSMÃO ROM, 2016).

Pode-se recolher da leitura freudiana que, diferentemente das neuroses, cuja libido afastada do mundo externo é substituída por outras na fantasia, na esquizofrenia, estarão concentradas no corpo sem um sustento simbólico de uma imagem de unicidade, levando o sujeito a experiências de sofrimento e sintomas corporais avassaladores. As alucinações na esquizofrenia, portanto, estão diretamente ligadas aos fenômenos corporais que decorrem da regressão a um estado que antecede o narcisismo. Esse movimento é o que diferenciaria a paranoia da esquizofrenia. A partir das postulações freudianas em relação à esquizofrenia, foi possível constatar que as dificuldades do laço social e $o$ isolamento são comuns nesse quadro clínico sinalizando para problemáticas na constituição psíquica desse sujeito, encenadas pelo funcionamento narcísico (GUSMÃO ROM, 2016).

\section{As manifestações de corpo na clínica da psicose}

Na psicose, o contato afetivo e social costuma ser substituído pelo investimento autoerótico na experiência de fragmentação corporal. Nesse estádio, as zonas erógenas são permeadas de pulsão, em que não existe ainda uma organização de corpo, para reconhecê-lo como um todo. Dizendo de outro modo, não há uma unidade do "eu" (FREUD S, 1914/1996).

A problemática do corpo presente na psicose é discutida por Freud em seu texto de 1914. Uma nova ação psíquica precisa acontecer para que essa pulsão despedaçada ganhe contorno e totalidade, ou seja, para que o sujeito se constitua. A constituição de um corpo só será possível se este for investido de marcas advindas do outro. A essa nova ação psíquica nomeará de Estádio do Espelho (GUSMÃO ROM, 2016).

Lacan, com seu retorno à teoria do narcisismo em Freud, desenvolve o estudo sobre o processo de constituição da imagem corporal do sujeito, partindo-se da identificação com a imagem do Outro. Ao teorizar sobre a fase do estádio do espelho, ele explica que a identificação com o Outro faz com que a criança invista em si mesma, o que a leva a vivenciar o narcisismo primário. Esse processo é organizado em três tempos. No primeiro momento, não há uma distinção entre o Eu e o Outro, assim, ao olhar para o espelho, a criança não vê uma diferença. No segundo momento, a criança já consegue, aos poucos, diferenciar uma imagem do Outro real. Já no terceiro, perceberá que a imagem do espelho trata de si mesma, momento em que se estabelecem as bordas do próprio corpo, a diferença entre o Eu e o Outro surgirá (GUSMÃO ROM, 2016).

Para Gusmão ROM (2016), portanto, a partir de sua leitura lacaniana, a linguagem é fundamental no processo constitutivo do sujeito, uma vez que é ela que sustentará a experiência do espelho no campo das relações. Nesse sentido, acentua que o Outro é indispensável neste processo constitutivo, pois é a partir dessa referência que a criança passará a ter uma noção do próprio corpo.

Nessa perspectiva, pode-se relacionar os fenômenos das psicoses ao seu mecanismo constitutivo específico, à foraclusão do Nome-do-Pai. A ausência da metáfora paterna, necessária para a constituição do corpo, produz fenômenos que invadem o sujeito. Para Lacan J (1955/1998), os sintomas comuns na esquizofrenia: a fragmentação corporal, a estranheza com o próprio corpo, as alucinações e os delírios.

\section{$O$ desencadeamento psicótico e a estabilização}

Partindo-se de suas observações clínicas, Freud S (1924) com o texto "A perda da realidade na neurose e na psicose" reformula algumas questões a respeito da relação do sujeito neurótico e psicótico com a realidade externa. Ele analisa que a diferença entre neurose e psicose não expressa exclusivamente pela sua relação com a realidade, mas, sim, com as formas como os mecanismos de defesa vão se processar em cada quadro clínico. No final da sua obra, Freud já se vê no movimento de querer fundamentar um mecanismo que não fosse o recalque para as neuroses narcísicas já denominadas de psicose. Ele teria sido impreciso na definição de um mecanismo para as psicoses, contudo ele deixa a ideia da Verwerfung, um nome que atribuiu a um mecanismo mais radical desses quadros clínicos (SANTOS TC e OLIVEIRA FLG, 2012). 
$\mathrm{Na}$ teoria freudiana, a Verwerfung é definida como um mecanismo próprio das psicoses, que significa a renegação da representação da ideia e do afeto. Esse termo foi utilizado por Freud no "texto homem dos lobos" (1918). Os equívocos teóricos oriundos desse caso o impediram que evoluísse com este mecanismo. Para Lacan, a Verwerfung refere-se a uma defesa mais radical que existe no campo da psicose, a exclusão do significante primordial Nome-do-Pai (OLIVEIRA RAS, 2008).

Tendo em vista alguns impasses teóricos não respondidos por Freud sobre o campo das psicoses, a tese lacaniana sobre essa clínica é produzida. Nessa direção, considera a existência de três formas particulares de resposta do sujeito diante da castração, sendo elas Neurose, Psicose e Perversão, conforme o mecanismo utilizado, isto é, a forma como o sujeito lida com a interdição na relação dele com o outro cuidador que vai determinar a sua estrutura (SANTOS TC e OLIVEIRA FLG, 2012).

Cada uma dessas estruturas clínicas apresenta modos diferentes de o sujeito lidar com as relações de perdas objetais. Na neurose, o mecanismo de defesa é esconder da consciência o conteúdo que causa malestar. Na psicose, seu mecanismo se expressa pela rejeição do significante do Nome-do-Pai no simbólico. Na perversão, o mecanismo é a negação da castração (GUERRA AMC, 2010).

O significante Nome-do-Pai é conceituado por Lacan, como o operador que permite separar as neuroses das psicoses. Desse modo, as estruturas clínicas são determinadas a partir da entrada da metáfora paterna. De acordo com Oliveira RAS (2008), "A metáfora paterna é a condição para a operação da lei no Outro, por meio da produção de uma significação que ordena em torno de si própria o conjunto dos significantes, impossibilitando que estes saiam dos limites do simbólico".

Conforme Lacan J (1955/1998), a foraclusão do Nome-do-Pai refere-se à impossibilidade de o sujeito nomear-se. É nesse ponto vazio que surge ao psicótico a impossibilidade de resposta diante da castração, devido à precariedade no registro do simbólico. Nesse sentido, o sujeito se remaneja para articular uma resposta subjetiva, desprovida de balizas simbólicas, o que leva o seu retorno ao real. A partir da ausência dessa operação metafórica, propiciadora da organização do sujeito no mundo, que se suscitaria o desencadeamento da psicose.

Em "De uma questão preliminar a todo tratamento possível da psicose" (1958), Lacan formaliza a teoria de desencadeamento na psicose tendo por base a teoria freudiana acerca da dissolução do Édipo. Nesse sentido, ao se debruçar sobre o inconsciente estruturado como linguagem, norteado pela primazia do simbólico, evidencia-se que, em decorrência da ausência do significante Nome-do-Pai e da significação fálica, as alucinações e alterações na linguagem retornam ao real, isto é, aquilo que foi abolido simbolicamente desencadeará o real (DRUMMOND C, 1999).

Lacan, em seu seminário sobre as psicoses (1955/1998) destaca três condições subjetivas do desencadeamento na psicose.

O primeiro aspecto do desencadeamento é a peculiaridade de o sujeito psicótico relacionar-se com a linguagem, a não dialética no discurso, resultante da foraclusão do significante Nome-do-Pai no processo constitucional da estrutura desse sujeito. A alteração no processo da linguagem e a precariedade no registro do simbólico no campo da psicose implicam uma impossibilidade de a metáfora paterna operar, fazendo com que o sujeito apresente manifestações bem características dessa clínica, como exemplo acontecimentos de corpo, alucinações e delírios (GUERRA AMC, 2010).

A segunda particularidade refere-se à ruptura da identificação imaginária do psicótico com o outro absoluto. Nesse sentido, quando a amarração do sujeito ao apêndice do outro que o sustenta é abalada pode levá-lo a um desencadeamento. A terceira condição ocorre quando o Nome-do-Pai, que fora foracluído, é evocado em posição simbólica ao sujeito. Ao ser convocado a responder a esse significante paterno, 0 desencadeamento da psicose acontece (GUERRA AMC, 2010).

As formulações lacanianas sobre possíveis saídas e invenções para a estabilização na clínica da psicose nos direciona para um tratamento possível. No percurso de sua escrita, Lacan apresenta soluções subjetivas que funcionam como uma amarração dos registros imaginários, real e simbólicos (GUERRA AMC, 2010). 


\section{A questão da transferência na psicose}

Desde Freud, a transferência é, sem dúvida, o pilar de todo o processo psicanalítico. O seu conceito é imprescindível para que se possa pensar na condução clínica. Freud afirma que não há tratamento psicanalítico sem transferência (FREUD S, 1916).

Na obra lacaniana tem-se uma transformação do fenômeno transferência. Lacan, ao fazer uma releitura sobre a transferência da obra de Freud, desenvolve a ideia de Sujeito Suposto Saber. Esse lugar agora não é de um para o outro, senão, de um para o grande outro. A transferência é estabelecida quando o analista ocupa o lugar de Sujeito Suposto Saber, ou seja, o paciente supõe que o analista sabe algo do seu sofrimento, do seu desejo, há uma aposta de que o Outro detém um saber sobre o seu inconsciente. Nesse sentido, o paciente coloca o analista nesse lugar de quem detém um poder sobre o seu sentido, pois, na estruturação desse sujeito, quem detém o poder da significação sobre ele é o Outro (MILLER, 1988).

Tendo como referência a clínica com a psicose, Freud, em seus estudos iniciais sobre as psicoses, apontou os limites da psicanálise nessa clínica em consequência do abandono das relações objetais. No entanto, a partir de algumas elaborações a respeito do tema, os seus escritos apresentaram outros contornos para a condução dessa clínica. Diferente de Freud, Lacan sustenta em seus estudos que, dentro do tratamento psicanalítico, há a possibilidade de laço transferencial na clínica da psicose, no entanto, destaca que a sua manifestação se estabelece de outro modo, pela via da erotomania, e o analista frente a isso ocupa outro lugar que não o de Sujeito Suposto Saber (GUERRA AMC, 2010).

Lacan (1955/1998) valendo-se dos estudos freudianos, avançou a teorização na direção do tratamento da psicose, fundamentado na perspectiva psicanalítica, a fim de desenvolver a compreensão acerca das psicoses e, em seguida, relacioná-las ao delírio da erotomania. Ele explica que a transferência na clínica da psicose, dentro do tratamento psicanalítico, se estabelece por meio de uma forma de amor projetiva. O seu aparecimento durante o percurso analítico é pela via da erotomania e o analista, frente a isso, ocupa outro lugar.

A partir do entendimento dessas particularidades, compreende-se, portanto, que a clínica proposta por Lacan no "Seminário III- As psicoses" é o ponto de partida para que se possa pensar em possibilidades para operar e manejar a transferência na psicose. "Nesta, o analista sustenta os significantes do sujeito tendo como princípio ético o respeito àquilo que o próprio paciente traz na transferência" (HERMANN, 2004, P.286).

O manejo clínico da transferência na psicose, marcada por outra organização, é direcionada a apaziguar este ponto de real que invade o sujeito, para que este construa saídas subjetivas. $O$ analista deverá absterse de dar respostas, quando convocado a preencher o buraco causado pela ausência do significante paterno, através do seu dizer. "No tratamento da psicose é preciso que o analista saiba responder às condições exigidas pelo sujeito psicótico, a saber, que saiba "saber-não-saber" (BAIO V, 1999, P. 89). Esse movimento possibilita ao analista traçar intervenções no sentido de fazer barra ao gozo do outro invasivo.

\section{Impasses institucionais na clínica da psicose}

A psicanálise nos ensina que a transferência com o sujeito psicótico é diferente da neurose. Isso porque o psicótico tem vínculo frouxo, mas, se há transferência, quando querem e precisam, procuram o serviço. Diante disso, para não recuar diante à psicose, conforme se recomenda Lacan, é preciso considerar o modo próprio de funcionamento clínico estrutural dos sujeitos (LACAN J, 1955/1988)

Entendemos que a inserção da psicanálise em outros contextos distintos do consultório particular é complexa e muitas vezes se torna um grande desafio, dado que os princípios éticos que regem a psicanálise são opostos à lógica de funcionamento padronizado de algumas instituições. Segundo Meyer GRA (2016) a ética da psicanálise é definida como uma ética que aposta na escuta do sujeito, no um a um, considerando este como responsável pela direção do seu tratamento.

Uma discussão presente nas literaturas visitadas sustenta que o discurso psicanalítico é incompatível com o discurso burocrático da instituição. Tais discussões apontam que a lógica institucional é pautada em um 
saber universal que não leva em conta a singularidade de cada sujeito. Essa questão torna-se muito preocupante e diferente dos fundamentos da psicanálise (LIMA FMS, 2009).

Tendo consciência dessa complexidade, a prática clínica no âmbito institucional nos permite refletir sobre como o modelo paradigmático da instituição generaliza a subjetividade de cada sujeito. Além disso, muitas vezes, a instituição impõe um ideal de funcionamento que não corresponde, por exemplo, à forma de funcionar de um sujeito psicótico. Os profissionais da saúde mental, se apropriando das contribuições da psicanálise podem colocar um ponto de basta a este funcionamento institucional, inventando um modo diferente de clínica que respeite as particularidades dos sujeitos (LIMA FMS, 2009).

\section{CONSIDERAÇÕES FINAIS}

Os referenciais da psicanálise contribuem para a explicação de impasses clínicos surgidos na prática profissional. A realização deste estudo possibilitou capturar contribuições importantes da psicanálise para as particularidades da clínica da psicose. As dificuldades do laço social e o isolamento sinalizam para problemáticas na constituição psíquica desse sujeito, encenadas pelo funcionamento narcísico. $O$ uso do corpo seria uma via subjetiva para a construção de saídas na esquizofrenia. O desencadeamento psicótico denuncia a forma peculiar como o sujeito psicótico relaciona-se com a linguagem, a não dialética no discurso, resultante da foraclusão do significante Nome-do-Pai no processo constitucional da estrutura desse sujeito. As alterações no processo da linguagem implicam nas manifestações bem características dessa clínica, como exemplo acontecimentos de corpo, alucinações e delírios. Apesar disso, Lacan em seu ensino propõe a possibilidade de pensar o manejo da transferência na clínica da psicose pela via do secretariado.

\section{REFERÊNCIAS}

1. BAIO V. O ato a partir de muitos. Psicanálise e Saúde mental: Revista da Escola Brasileira de Psicanálise, 1999; (13), 66-73.

2. DRUMMOND C. O desencadeamento da psicose. Revista Curinga EBP - MG, 1999; n.13, p.115-119. set.

3. FREUD S. A perda da realidade na neurose e na psicose. Edição standard brasileira das obras psicológicas completas de Sigmund Freud. Rio de Janeiro, Imago Editora, 1924/1996; 19: 229-234.

4. FREUD S. Neurose e psicose. Edição standard brasileira das obras psicológicas completas de Sigmund Freud. Rio de Janeiro, Imago Editora, 1924/1996; 19: 201-209.

5. FREUD S. A teoria da libido e o narcisismo (Conferência XXVI). Edição standard brasileira das obras psicológicas completas de Sigmund Freud. Rio de Janeiro. Imago Editora, 1916/1996; 15: 01-219.

6. FREUD S. Notas psicanalíticas sobre um relato autobiográfico de um caso de paranoia (Dementia paranoides. Rio de Janeiro: Imago Editora, 1911/1996. 210 p.

7. FREUD S. Sobre o Narcisismo: uma introdução. Edição standard brasileira das obras psicológicas completas de Sigmund Freud. Rio de Janeiro. Imago Editora,1914/1996; 14: 89-122.

8. GUERRA AMC. A psicose. Rio de Janeiro: Zahar, 2010; 88p.

9. GUSMÃO ROM. A Esquizofrenia e as experiências idiossincráticas corporais: Uma visão psicanalítica. Dissertação (Mestrado em Teoria Psicanalítica) - Programa de Pós-graduação em Teoria Psicanalítica/ IP/, Universidade Federal Rio de Janeiro - UFRJ, Rio de Janeiro, 2016; 136p.

10. LACAN J. De uma Questão Preliminar a todo Tratamento possível na Psicose. Trad. Rio de Janeiro: Zahar Editora, 1958/1998; 2: 537-590.

11. LACAN J. O Seminário, livro 3: As Psicoses. Trad. Rio de Janeiro: Zahar Editora, 1955/ 1998; 368p.

12. LIMA FMS. Sobre um tratamento psicanalítico da psicose na clínica institucional. Dissertação (Mestrado em Psicanalise) - Programa de Pós-Graduação em Psicanálise, Universidade Estadual do Rio de Janeiro, Rio de Janeiro. 2009; 105p.

13. MEYER GRA. Psicanálise na instituição de saúde mental. Revista Asephallus de Orientação Lacaniana, 2016; 11(22): 108-121.

14. OLIVEIRA RAS. A Invenção do corpo nas psicoses: impasses e soluções para o aparelhamento da libido e a construção da imagem corporal. Tese (doutorado em teoria psicanalítica) - Programa de Pós-Graduação em Teoria Psicanalítica/IP. Universidade Federal do Rio de Janeiro, Rio de Janeiro, 2008; 213p.

15. SANTOS TC, OLIVEIRA FLG. Teoria e clinica psicológica da psicose em Freud e Lacan. Psicologia em Estudo, 2012; 17(1): 73-82. 